\title{
REPRESENTAÇÕES DO ESPAÇO E O ESPAÇO COMO REPRESENTAÇÃO
}

Representations of space and space of representation

\section{Carolina da Rocha Lima Borges}

Carolina Borges: arquiteta, Doutoranda em Estética e Semiótica pela FAU-UnB e mestre pela mesma instituição, atualmente é professora no curso de Arquitetura e Urbanismo da Universidade Católica de Brasilia.

\section{Resumo}

As noções de espacialidade, por serem culturais e construídas, são mutáveis e podem se manifestar de diversas maneiras. A representação em perspectiva, por exemplo, é uma das formas mais concretas de se objetivar e registrar tais noções. É sabido que o desenho em perspectiva nem sempre foi construído do modo como conhecemos hoje: antes do cânone renascentista, essas representações não se limitavam ao princípio de geometrização do mundo, onde o homem se via como expectador no centro de um cenário de uma arquitetura dominante. Registros demonstram que as formas mais usuais de se representar o espaço nas culturas da antiguidade clássica e da Idade Média eram bastante intuitivas e determinadas pelo ponto de vista subjetivo do homem, que se apresentava como protagonista do espaço e ganhava legitimidade por meio de um percurso.

Palavras-chave: infinito, perspectiva, espaço, cenário.

\section{Abstract}

The notions of spatiality are cultural, constructed and mutable, and can be manifested in different ways. Perspective representation, for example, is one of the most concrete ways of objectifying and recording such notions. It is well known that the drawing in perspective was not always constructed in the way we know today: before the Renaissance canon, these representations were not limited to the principle of geometrization of the world, where the man viewed himself as a spectator in the center of a setting of a dominant architecture. Records show that the most usual forms of representing space in the cultures of Classical Antiquity and the Middle Ages were quite intuitive and determined by the subjective point of view of man, who presented himself as the protagonist of the space, acquiring legitimacy walking along a pathway.

Keywords: infinity, perspective, space, scenery. 


\section{INTRODUÇÃO \\ como é doce a perspectiva! \\ pado Uccello}

1

Apud Giedion, 2004, pg.59
A mais usual representação em perspectiva nos dias de hoje, a linear, promove uma conversão do espaço real em espaço matemático e homogêneo, simulando uma imagem do infinito não apreendida pela experiência, ou seja, a perspectiva seria uma representação visual do conceito do infinito. Panofsky explica que a noção de infinitude é uma abstração da realidade (sendo "realidade" a efetiva impressão visual do sujeito), e que a descoberta do ponto de fuga, enquanto imagem dos pontos infinitamente distantes de todas as ortogonais, constitui "o símbolo concreto da descoberta do próprio infinito" (Panofsky, 1999, pag. 54), e completa:

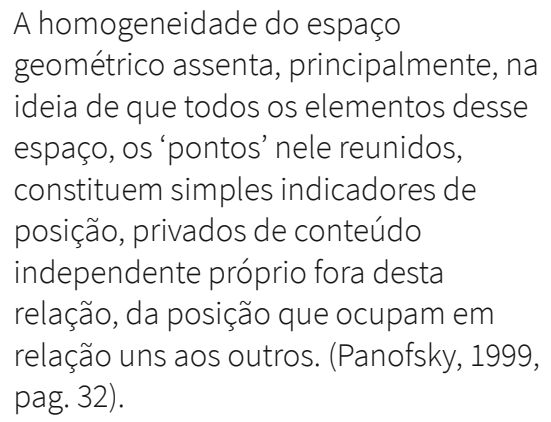

Sobre a relação da espacialidade e a autonomia/heteronomia dos elementos do espaço da obra, o teórico da arte Heinrich Wölfflin faz uma outra interpretação. Segundo ele, os elementos contidos em uma perspectiva linear têm a pluralidade como característica, que, apesar da evidente ligação conceitual e formal dos elementos no conjunto, cada um possui uma autonomia - caso "retirado" do seu contexto, continuaria "dizendo" aquilo que era dito inicialmente.

Tomemos como exemplo duas obras de artistas diferentes, feitas em períodos diferentes (renascimento e barroco), mas que possuem o mesmo tema - A Última Ceia. O espaço utópico, geométrico e homogêneo na obra de Leonardo da Vinci tem um ponto de fuga central onde Jesus está posicionado, de modo que o olhar do observador é direcionado para este centro e, num segundo momento, os outros elementos são apreendidos. Não há conflito. As figuras são lidas de um modo linear e cada um dos personagens parece ter uma personalidade própria e possui uma certa independência do conjunto - como dito, caso retirado, continuaria com a sua autonomia.
Na Santa Ceia de Tintoretto, todos os personagens parecem estar ligados entre si - caso fossem isolados, perderiam o sentido. Ao mesmo tempo, ocorre uma leitura conflituosa: Jesus não está no centro, está deslocado, e o único elemento que o diferencia dos outros personagens é a aura dourada. Fora esse elemento, é um homem comum como os outros que estão na tela. Sua luz também não é a única: no canto superior esquerdo existe uma "pomba" que concorre com a imagem de Jesus. A leitura faz um vai e volta que direciona para mais de um ponto focal ao mesmo tempo.

O espaço infinito da obra de Leonardo acontece nesse direcionamento para dentro do quadro, enquanto que no Tintoretto a imagem é cíclica. O movimento centrífugo das figuras na obra de Tintoretto contribui para criar a ilusão de que o espaço da cena não se confina ao painel, mas se alarga em todos os sentidos, como se a moldura fosse a janela, através da qual podemos ver parte de uma realidade contínua. $\mathrm{O}$ espaço da pintura sai da sua materialidade e se propaga em todas as direções, ultrapassando o "lugar" representado, "sendo, exatamente, o caráter finito do quadro a chamar a atenção para a infinitude e continuidade do espaço" (Panofsky, 1999, pag. 57).

Em um desenho em perspectiva linear, o espaço real visualmente finito é convertido em um plano bidimensional e é representado de uma forma ideal dentro dos princípios da geometria naquele suporte bidimensional. Essa perspectiva se converte em uma ideia de infinitude do espaço. Sobre o assunto, Sigfried Giedion completa:

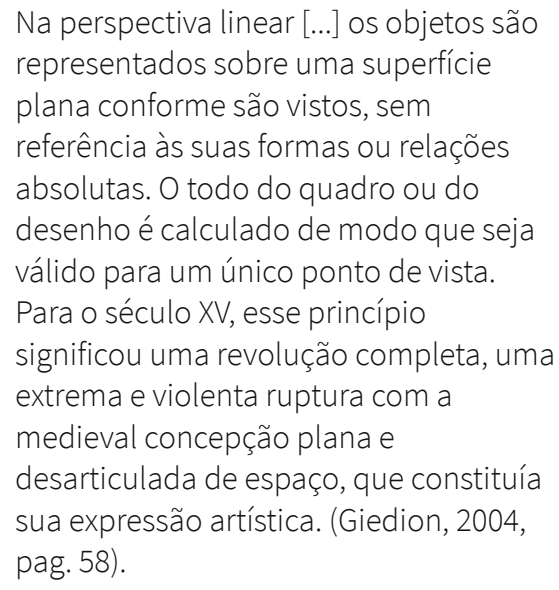

Além da ideia da representação do espaço em um plano bidimensional, tem-se também a arquitetura, o espaço real propriamente dito, construído para ser visto por meio de um ponto fixo central. Já não estamos mais falando de uma representação do 


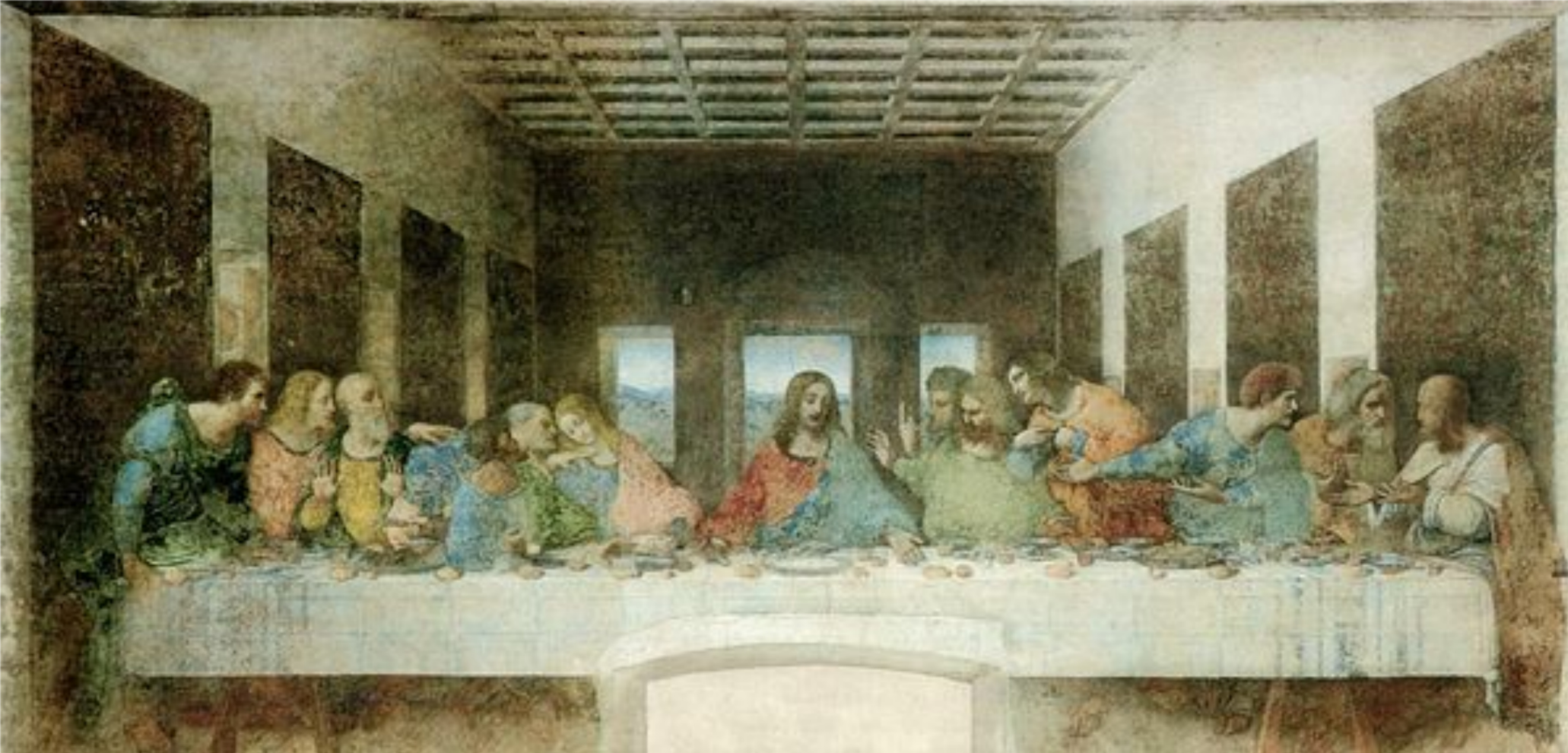

FIGURA 1. Leonardo da Vinci. A Última Ceia. Santa Maria delle Grazie. Milão, entre 1495 e 1498.

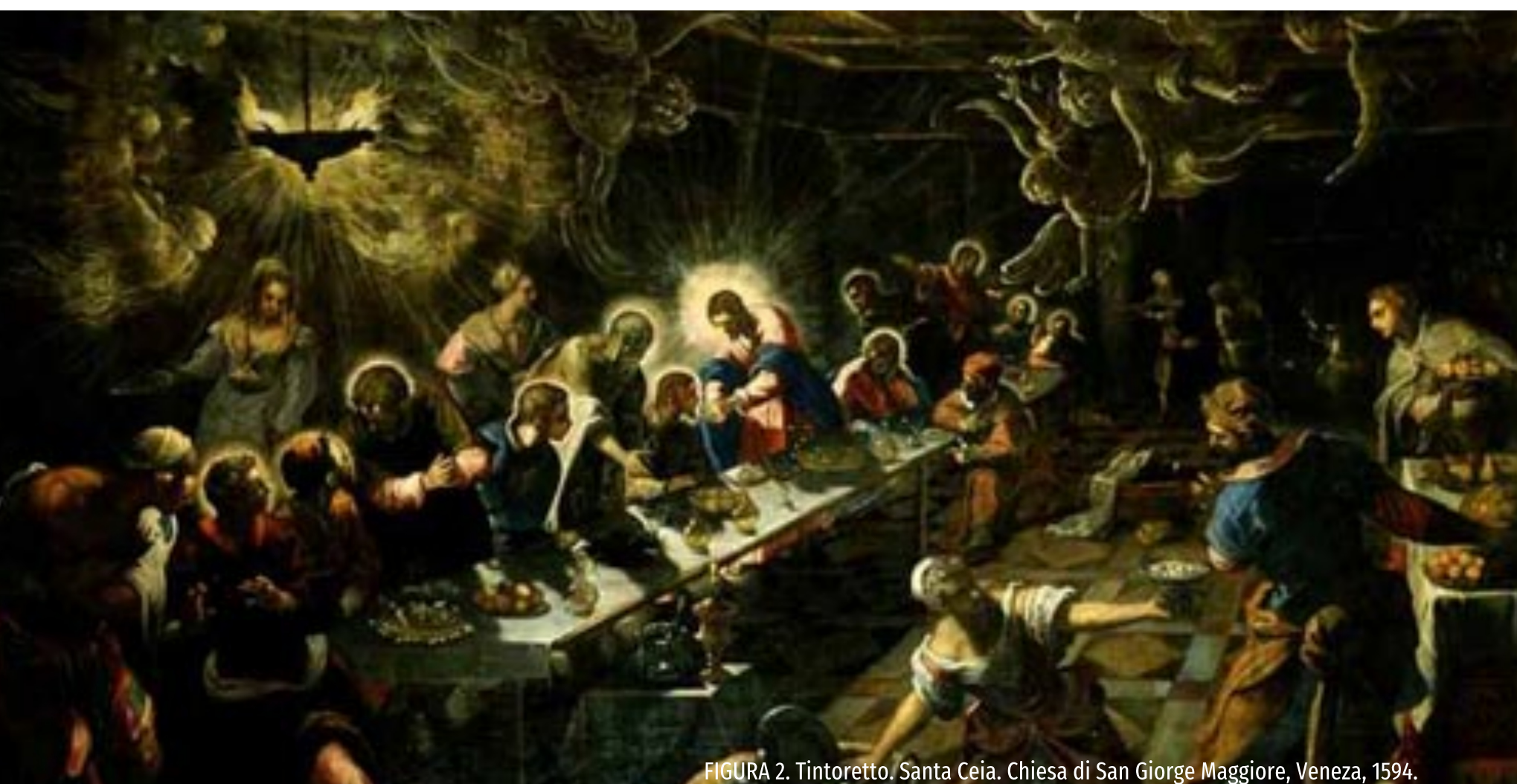


espaço, mas se trata agora do espaço como representação de uma ideia, de uma ordem, de um designo e de um propósito. Sendo que o homem é um protagonista, hora principal, hora secundário, hora expectador, hora atuante, nesse princípio de geometrização do mundo que o situa no centro de um cenário de uma arquitetura dominante (no caso renascentista). O espaço se converte em uma representação de uma ideia e manifestação de um modo de ver o mundo.

Panofsky, 1999, pag. 37.

\section{REPRESENTAÇÕES}

DO ESPAÇO

O conceito de espaço para os antigos surge com Platão, que o designa como Khora, lugar ou receptáculo, onde, existindo um lugar, este está contido noutro lugar e assim sucessivamente. Para Aristóteles, os corpos não são assimilados segundo um sistema homogêneo e infinito de relações dimensionais, eles são os conteúdos justapostos de um recipiente finito. Não existe o infinito que ultrapasse o ser dos objetos isolados (a própria esfera das estrelas “imóveis" era um objeto isolado). 0 espaço é um lugar no qual um corpo está contido, o lugar é definido como o limite de cada corpo. Concluímos que o espaço era delimitado enquanto "lugar" e que a noção de infinitude não era algo intuitivo.
Essa consciência de espacialidade dos antigos era coerente com os seus desenhos em perspectiva: 0 campo de visão era entendido como uma esfera e as representações em perspectiva se davam em função das distorções visuais que acontecem devido a essa configuração esférica, sendo maiores na medida em que se aumenta o ângulo de visão. As relação entre as grandezas dos objetos não se exprimiam em medidas de comprimento simples, mas em graus de ângulos. Para eles, uma perspectiva em linhas retas poderia parecer curva, por outro lado, uma quadrícula levemente curva, ao nosso olhar, pareceria ser reta, dependendo do ângulo de visão: ${ }^{2}$

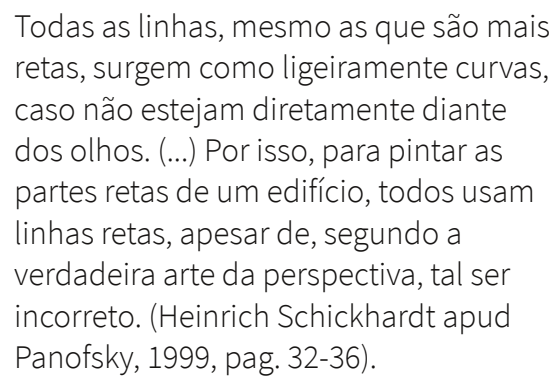

Nessas representações dos antigos, a chamada perspectiva angular, as dimensões visuais não são inversamente proporcionais às distâncias, ao contrário da perspectiva linear renascentista, que estabelece um método que rejeita o axioma dos ângulos ao representar elementos tridimensionais em superfícies
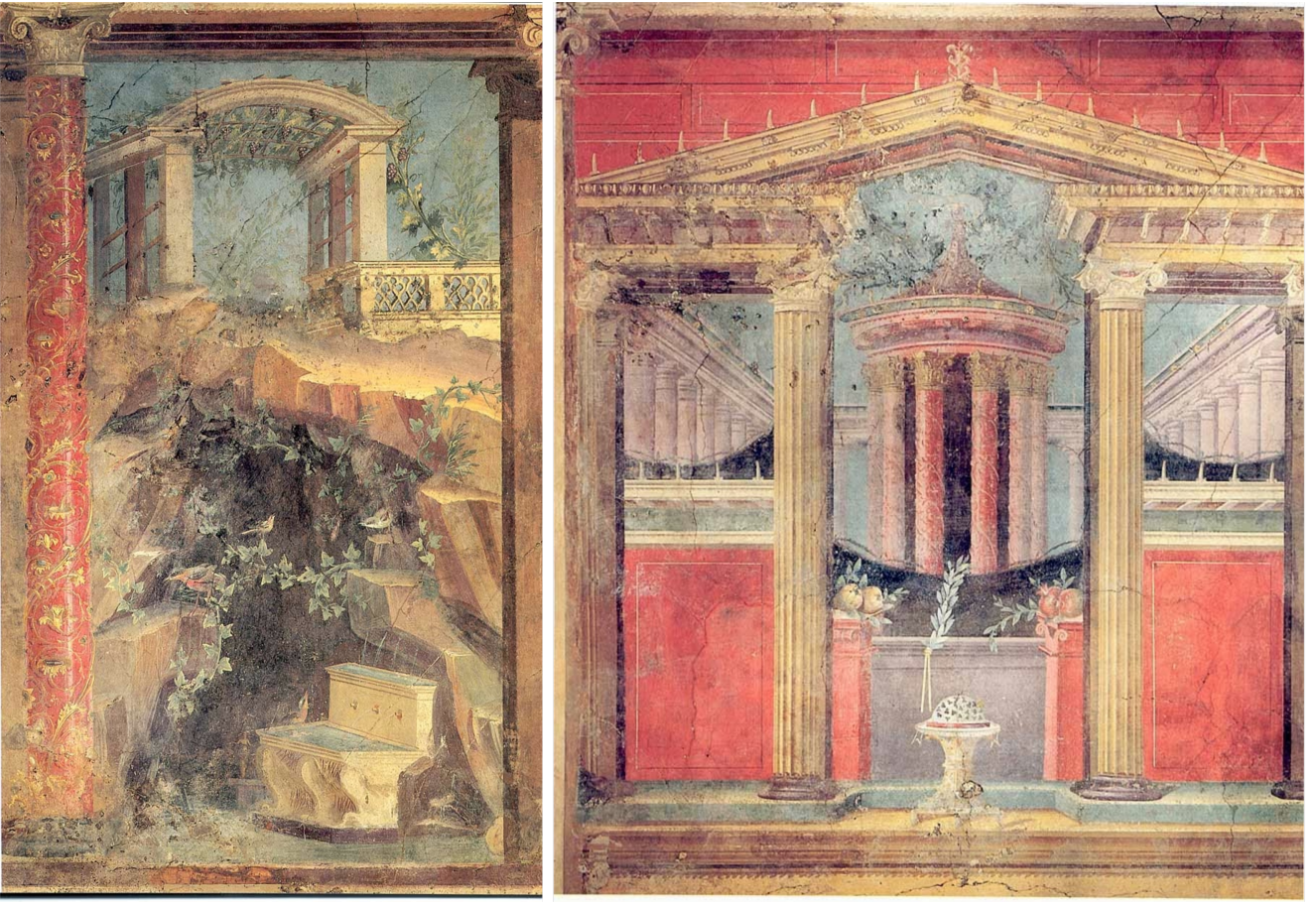

FIGURAS 3 E 4. Pintura mural de

Pompéia no Segundo Estilo.

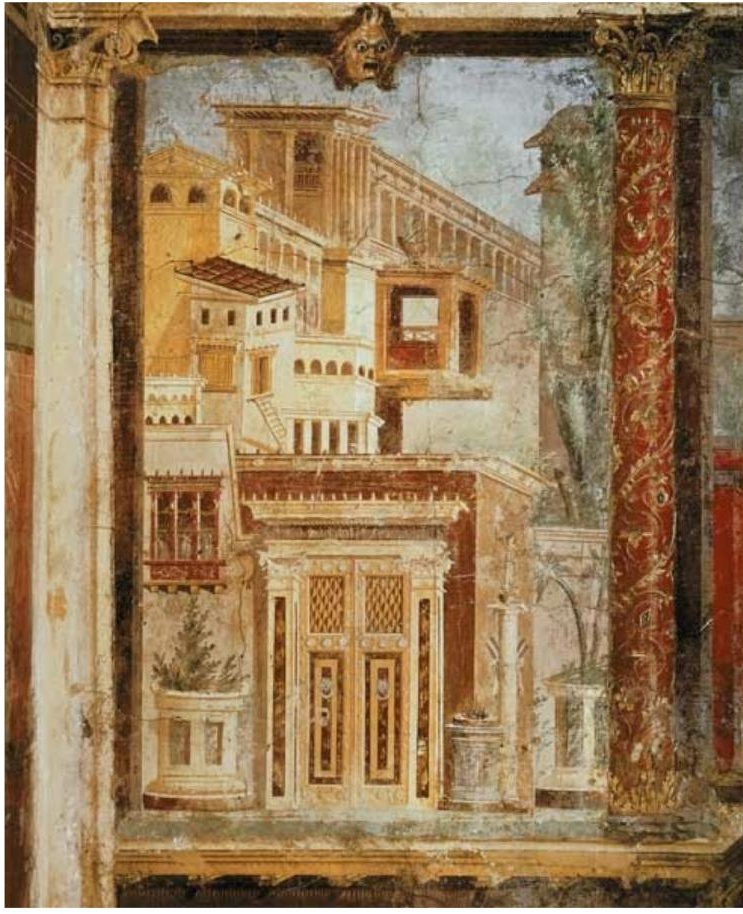

FIGURA 5. Pintura mural no Segundo Estilo da Villa de Publius Fannius Sinistor, Boscoreale, perto de Pompeia. Meados do séc. I a.C. 
2012, pag.44). O cenário é uma simulação, diferente de uma pintura pura, que busca representar a verdade: "um cenário é um biombo que oculta a luz da existência, enquanto a pintura pura é uma janela inteiramente aberta para a realidade" (Floriênski, 2012, pag.38).

Os murais nas casas de Pompéia, apesar de aparentemente formarem cenários a partir da combinação entre as pinturas e os espaços dos ambientes, não estavam ali para duplicar a realidade, mas alterar e brincar com o espaço. Se a pintura mural interna de uma casa obedecesse à precisão de regras de perspectiva, pretendendo enganar o observador, atingiria tal objetivo somente quando o observador estivesse imóvel em um determinado lugar do ambiente. No entanto, a casa habitada não era um teatro e seu habitante não estava preso em um único lugar, além de não ser um mero expectador.

De acordo com Floriênski (2012, pag. 46), o pintor fazia as pinturas dando perspectivas aproximadas para vários pontos de vista e assim renunciava à arte dos simulacros, já que nitidamente não tinha a intensão ludibriar com suas pinturas fantasiosas, ou simulando profundidades que não são reais. Nesse sentido, essas pinturas estariam mais próximas da realidade, na medida em que assumia um status de fantasia, fortalecendo o real por se opor a ele, e se afastariam dos cenários (no sentido de simulação). 0 "decorador" se transformaria assim no artista, não por seguir as regras de perspectiva, mas por se afastar delas.

A criação de um cenário acontece na medida em que o artista considera que o observador vai estar em um local pré-determinado, e todo o espaço é configurado para ser visto a partir daquele local. Não é que o observador não possa ou não deva se locomover, mas o espaço vai ser melhor visto a partir daqueles pontos definidos. Essa configuração faz aparecerem "pequenos mundos" dentro de outros mundos existentes, realidades paralelas criadas na tentativa de se mostrar suas próprias verdades.

Um dos casos onde mais se assume essa situação em que um plano é configurado para ser visto a partir de um ponto fixo, para que assim esse plano dialogue com o espaço e se converta também em espaço tridimensional, é a já citada "Última Ceia", de Leonardo da Vinci. Nesta obra, é o espaço arquitetônico (tridimensional) que define as linhas do plano do afresco (bidimensional), onde o ultimo simula uma tridimensionalidade que nega a sua planaridade original. Leonardo antecipa uma relação entre sujeito e obra que iria acontecer só no século XVII, na qual o observador, fora da tela, parece ser um elemento que "fecharia" a composição da pintura. $\mathrm{Na}$ última Ceia, o observador não faz parte da composição, mas se insere nela como uma testemunha que tudo vê, mas que não é visto pelos personagens da pintura. $\mathrm{O}$ observador teria um ponto privilegiado para melhor ver a composição - no meio da sala (refeitório), em uma distância de aproximadamente quinze metros perpendicularmente ao afresco.

Ainda sobre a Última Ceia, não é falso dizer que os personagens definem o lugar no afresco, onde, junto com os objetos da composição, são direcionados para um ponto de fuga central, manifestando assim a ideia de infinito. $O$ enquadramento da parede/ suporte do afresco normalmente deveria delimitar a composição, como a maioria das pinturas renascentistas fazem, tornando a composição "fechada". Esse fechamento não acontece especialmente na Última Ceia, se considerarmos o espaço da sala como sendo também parte da composição.

Diferente da obra de Leonardo, que avança o campo frontal e anterior ao plano da pintura, nas pinturas de Pompeia, a continuidade do espaço aparenta acontecer somente para detrás da tela. Essas pinturas representam uma fatia de realidades paralelas, uma janela que se abre para fora sem qualquer conexão com o espaço interno propriamente dito ou com as outras pinturas presentes no local - poderiam estar em qualquer local sem prejuízo na composição. Também não há um local privilegiado para o observador estar. 0 espaço das pinturas é finito e não representa cenários, apesar de muitas vezes aparentar fazê-lo.

\section{O Espaço como Representação}

A perspectiva científica desenvolvida no século XV se tornou um cânone que se mantém até os dias de hoje. De acordo com Giedion, "com a invenção da perspectiva, a moderna noção de individualismo encontrou sua contrapartida artística. Numa representação em perspectiva, cada elemento achase relacionado com um único ponto de vista, o do espectador" (2004, pag. 58). Como dito acima, todos teriam exatamente a mesma vista a partir do mesmo ponto de vista, não havendo um percurso no qual o sujeito escolhe os caminhos que iria seguir. Nesse sentido, a noção de "individualismo" que Giedion cita estaria mais para um "coletivismo", uma vez que a escolha aqui não é tributária do sujeito. 
dimensões individuais do sujeito se manifestam por meio de um percurso tributário do sujeito. Essa dicotomia é contraditória com os períodos em que aconteceram, já que o renascimento é marcado por um humanismo e a antiguidade clássica pela parca noção de individualismo, já que ainda estava trilhando os primeiros passos.

\section{COMENTÁRIOS CONCLUSIVOS}

A visão perspectiva do espaço é diferente da mera representação em perspectiva. No entanto, a representação é uma manifestação da noção de espaço que também irá se consolidar na ordenação da arquitetura na cidade. No espaço renascentista, a arquitetura ganha legitimidade objetiva, embora pareça que essa legitimidade foi dada ao homem, dada a sua posição privilegiada no centro da composição. Não é a composição que foi toda configurada para ser vista por esse homem no seu centro, delegando a este homem um status de personagem principal. É a arquitetura que domina o espaço e define um local para o homem, apesar de que as representações em perspectivas agiam mais em edifícios isolados do que propriamente no espaço em si.

Tal modo de esquematizar a realidade, por ser mais racional, privilegiava as dimensões objetivas do sujeito que a apreende, apesar não corresponder ao mundo real, pois não existem realidades que contenham em si um centro com um homem ocupando esse centro, logo, que esteja submetido a determinadas leis. Mesmo tendo o homem como centro da composição, essa representação o massifica ao desconsiderá-lo nas suas particularidades individuais, negando um percurso alternativo àquele já definido pelo ponto de fuga. Todas as questões estariam aparentemente resolvidas.

Nas pinturas da antiguidade clássica, especialmente nos murais de Pompéia, a perspectiva com pontos de fuga excêntricos reforça a impressão de nos encontrarmos diante de uma representação determinada pelo ponto de vista subjetivo de um observador que circula pelo espaço. Por levar em conta o caminho do observador, tal modo de representação parece considerar mais o sujeito na sua dimensão humana e individual do que uma perspectiva linear, que é vista sempre de um ponto estático onde todos teriam a mesma vista, desconsiderando o percurso e as particularidades de cada um. Nesse sentido, a perspectiva clássica era, por assim dizer, mais "afetiva" e intuitiva que a moderna, que por muitos é acusada de fria e impessoal.

\section{REFERÊNCIAS \\ BIBLIOGRÁFICAS}

ARISTÓTELES; HORÁCIO; LONGINO. A Poética Clássica. Tradução de Jaime Bruna. $7^{\circ}$ edição. São Paulo: Cultrix, 1997.

BENEVOLO, L. História da Cidade. São Paulo: Perspectiva, 1983.

GIEDION, S. Espaço, Tempo e Arquitetura: o Desenvolvimento de uma Nova Tradição. São Paulo: Martins Fontes, 2004.

PANOFSKY, E. Significado das Artes Visuais. Tradução de Maria Clara F. Kneese e J. Guinsburg. São Paulo: Perspectiva,1976.

PANOFSKY, Erwin. A Perspectiva como Forma Simbólica. Tradução de Elisabete Nunes. Lisboa: Edições 70, 1999.

La Perspectiva como Forma Simbólica. Tradução de Virginia Careaga. $4^{\circ}$ edição. Barcelona: Fabula Tusquets Editores, 2010.

. Idea: Contribuição à História do Conceito da Antiga Teoria da Arte. Tradução de Paulo Neves. $2^{\circ}$ Edição. São Paulo: Martins Fontes, 2013.

FLORIÊNSKI, Pável. A Perspectiva Inversa. São Paulo: Ed. 34, 2012.

RASMUSSEN, S. Arquitetura Vivenciada. $2^{\circ}$ edição. São Paulo: Martins Fontes, 1998.

RYKWERT, J. A Coluna Dançante: Sobre a Ordem na Arquitetura. Tradução de Andrea Loewen. São Paulo: ed. Perspectiva, 2015.

PLATÃO. O Sofista. Tradução de Carlos Alberto Nunes. Créditos da digitalização: Juscelino D. Rodrigues. Fonte Digital: Site "O Dialético", 2003. Endereço: http://www.odialetico.hpg.ig.com.br/

WOLFFLIN, H. Conceitos Fundamentais da Historia da Arte: O Problema da Evoluçã̃ dos Estilos na Arte mais Recente. Tradução de João Azenha Jr. $4^{\circ}$ edição. São Paulo: Martins Fontes, 2006. 